\title{
Biography
}

\section{Some Background on Dr Douglas Wilson's Achievements}

\author{
Douglas Wilson*
}

School of Medicine, Pharmacy and Health, Durham University, UK

\section{INTRODUCTION}

Douglas Wilson, was born to erstwhile Mary Wardell Hoffman from Sunderland, formerly of the Auxiliary Territorial Service (ATS), in Bishop Auckland, County Durham, England, on July $5^{\text {th }} 1940$, and lived around various airbases in England while his father, Thomas James Wilson, a rear-gunner from Cardiff, was engaged in the Royal Air force during the WWII conflict, before settling in the Penarth area, in Wales. Douglas was transferred from a Norwich infant's school (1943-1945) to one in Penarth (1946) and later succeeded in passing the 'The Eleven Plus' examination (1952), which was created by the 1944 Butler Education Act, that enabled him to study at Penarth County Grammar School (1952-1958) where he gained certificates in science and English that allowed him to take up a profession in industrial chemistry at British Resin Products (19581961), Sully, Penarth and attained technical qualifications in chemistry. He later joined Midland Silicones in Sully, Penarth (1962-1964: now Dow Corning) and carried out innovative research on catalytic systems for polyurethane foam production in which laboratory-based and pilotindustrial work led to full-scale industrial production in the automobile care seat industry at Cowley, Oxford. In recognition of his achievements, Douglas was chosen by the company, with similar achievers from some other companies in the UK, to attend a prestigious liberal studies group at Urchfont Manor, Wiltshire, England, which this year has closed its doors for the last time. Douglas studied chemistry, physics, mathematics and geology at a number of technical colleges whilst working as a junior chemist.

To further develop his passion for science, Douglas graduated at the University of Wales at Aberystwyth/ Cardiff and among the subjects studied were chemistry, biochemistry, agricultural biochemistry, geology, mathematics, economics and economic history and geology but he had the good fortune to be influenced by Dr Keith Griffiths who had links with the University of Minnesota, and was Director of the Tenovus Institute for Cancer Research at The Welsh National School of Medicine (later University of Wales College of Medicine) in Cardiff from where Douglas later obtained his $\mathrm{PhD}$ and $\mathrm{DSc}$ from the University of Wales. Douglas was

\footnotetext{
*Address correspondence to this author at the School of Medicine, Pharmacy and Health, Durham, UK; Tel: + 4419133 40825;

Fax:+44 19133 40346; E-mail: dww@tsimtsoum.net
}

given the opportunity to work at the Endocrine Research Unit, Cancer Institute, Melbourne, Victoria, located on the erstwhile site of the Peter MacCallum Cancer Institute, Little Lonsdale Street, part of the University of Melbourne, on endocrine aspects of breast cancer risk (1969-1971); where he undertook formal studies on statistics and also collaborated with the Honeywell Computer Time-Sharing Service, Melbourne, i.a. on the optimisation of protein-ligand interactions. He gave lectures and talks mainly at the Australian Endocrine Society Meetings (1970-1971) in Canberra, Melbourne and Sydney and the $4^{\text {th }}$ Asia and Oceania Congress of Endocrinology at Auckland ( 1971) on steroid-receptor optimisation for immunometric assays. He returned to the Tenovus Institute and continued his research work, vide infra. Further degrees in biological sciences, psychology, Latin and Greek and Religious studies, etc, were to follow later in life.

\section{CANCER RESEARCH AND RELATED DISCIPLINES}

Douglas Wilson began his medico-scientific career at the Tenovus Institute for Cancer Research on the $29^{\text {th }}$ August 1966, and sought to understand the role that steroid hormones may have in determining breast cancer risk or their value in predicting the response of women with advanced breast cancer to endocrine ablation. This work involved the measurement of androgen and 17 $\alpha$-hydroxycorticosteroid concentrations in the urine of healthy women, those with benign breast disease or those with primary or advanced breast cancer, and formed part of a collaborative study between Dr (later Professor) Keith Griffiths and Professor (later Sir) Patrick Forrest, Department of Surgery, Welsh National School of Medicine (Gleave, E.N., Wilson, D., Griffiths, K., Cameron, E.H.D., Campbell, H., and Forrest A.P.M. (1970). Urinary Steroid and Breast Disease. In "The $10^{\text {th }}$ Annual International Cancer Congress - Abstracts". Eds Cumley, R.W. and McCay, Joan E., Publ. University of Texas, Houston, pp527/528). He then studied at Melbourne University (1969-1971) before returning in 1971.

In the years that followed, 1971-1991, the quest for knowledge of risk and prognostic factors continued in endocrine cancer, notably breast and prostate, and this necessitated an understanding of biological variations of hormones in body fluids and those analytical uncertainties that arose from emerging radioimmunoassay. Douglas' major contributions to science have been in: 
a The development of chronoendocrinology and chronobiology, particularly in the recognition and quantification of hormone rhythms, especially in saliva, and in the study of breast skin temperature rhythms for the identification of the breast at risk of cancer;

b The identification of prognostic factors and related work in breast and prostatic cancer; and

c The development of statistical techniques and computer programs to measure and monitor analytical uncertainties in hormone estimations using radioimmunoassay and related techniques. This work laid the foundations for the National External Quality Assurance Schemes for steroid hormones in the United Kingdom.

Studies in statistics, computing and endocrinology generally supported these major themes of his research. The need for up-to-date information on these major topics led, in 1973, to the development of an information retrieval system for accessing clinical and scientific references at a time when international databases were not readily available. Details of the research carried out under these major fields of scientific endeavour are now summarised.

\section{CHRONOBIOLOGY AND BREAST CANCER}

Without doubt, the visit of Professor Franz Halberg, Chronobiology Laboratories, Lyon Laboratories, University Minnesota, Minneapolis to the Tenovus Institute in 1976 was a highlight and a cornerstone of Douglas Wilson's future life bringing together his innermost thoughts on the vital force theory, cosmological and terrestrial evolution, which moreover, heralded new vistas in medicine. Professor Halberg and later Professor Germaine Cornelissen offered and gave unstinting support to Douglas: no words will ever be adequate to describe the value which these scientists have placed on his academic achievements which are now discussed. Key activities came in the establishment of a meeting on Chronobiotechnology_and Chronobiological Engineering. NATO Advanced Science Institutes Series. Scheving Lawrence E., Halberg Franz. \& Ehret Charles F. Dordrecht/Boston/Lancaster: Martinus Nijhoff Publishers. 141-188; Vice Presidency of the International Society for Civilization Diseases and the Environment (SIRMCE); Editorial Board of Chronobiologia; Member of the Board of the International Society for Chronobiology; and many others. With regard to SIRMCE, he was instrumental in organizing in Cardiff, a symposium on the Health of Inner Cities published in a number of issues by the Institute of Statisticians. He was responsible for proposing a resolution on blood pressure monitoring following a presentation in Brussels in 1995. He was guest of honour in Ahmadabad at a symposium that highlighted communication in the poor and illiterate. At the other end of the scale he opened a conference on waste disposal in high tech countries, in Yokohama, Japan. Many other such conferences were undertaken perhaps the most important was that he was on the Programme Committee, and attended the Congress in March 1988 on "Environment and Health: A Holistic Approach" sponsored by the Luxemburg Ministries of Environmental Health, The Commission of the European Communities, and The World Health Organization. At this meeting he read the paper by José M.R. Delgado on The
Electromagnetic and ideological pollution of the brain. In 1985 he received the Jules Verne Medal from the Mayor of Nantes and delivered a lecture to citizens of Nantes on mainly chronobiological aspects of breast cancer, as part of Europe against Cancer Programme.

A major contribution was made by the recognition that circadian rhythms were different in the healthy and cancerous breasts, or those at risk for cancer, which potentially offered a means by which breast cancer, benign breast disease, or even preneoplasia, i.e. the breast at risk, may be detected at an early stage of development. This project involved the development of statistical methods and computer software necessary for quantifying these rhythms and to the design and building of an ambulatory monitoring device for measuring breast temperature and the deployment and use in pilot studies on women at high breast cancer risk or controls. Studies of premenopausal women demonstrated monthly rhythms of breast temperature that may be exploited for aiding natural family planning, and for detecting the breast at risk. The recognition of well-defined age-incidence patterns for epitheliosis in cancer mastectomy specimens with possible attendant thermal abnormalities in vivo suggest a possible role that breast temperature measurements may have in detecting preneoplasia, or early malignancy.

Studies of hormone rhythms were directed towards an understanding of their involvement in the aetiology of endocrine cancer. In healthy men, circadian rhythms of cortisol and testosterone in saliva were investigated in subjects on an expedition to Spitzbergen, where their sleep-rest schedule was altered so as to investigate any resulting testicular response. These rhythms are of potential importance in patients with carcinoma of the prostate and in quantifying stress under shift-work conditions. Rhythms of prolactin, a possible risk factor for breast cancer, were also investigated in patients with breast cancer and in healthy subjects, but the complex integration of circadian, circatrigintan and circannual rhythms made their quantification difficult and their comparison in health and breast disease a costly programme of research. Monthly rhythms or patterns of salivary progesterone variation have been recognised in postmenarchal girls and an interesting relationship has been obtained between the incidence of ovulation and the number of years post menarche. The rate of development of mature ovulatory cycles appears to be greater in British girls compared to Thais, thus the increased exposure of the breast to ovarian hormones, such as progesterone, may be an important determinant of breast cancer risk. Salivary progesterone levels were also used to determine if this aspect of ovarian function was different in healthy women and in patients with breast disease. It would appear that progesterone secretion is not different in women with primary breast cancer, benign disease or their age-matched controls. Similarly, studies of adrenal hormones in saliva failed to detect adrenal dysfunction in postmenopausal women with breast cancer. The usefulness of salivary steroid hormone measurement in studies of endocrine cancer, laboratory medicine and epidemiology was indicated in reviews on this topic.

In breast cancer studies, conducted mainly in collaboration between the Tenovus Institute and the Department of Surgery, City Hospital, Nottingham, considerable emphasis 
was placed on elucidation the prognostic value of various clinical and biochemical variables. This prognostic vale was measured in terms of predicting their influence on the duration of the disease-free interval or the patient's survival following disease recurrence. These variables included carcinoembryonic antigen, steroid hormones, oestrogen receptor status (ER) of the primary tumour, stage of disease, histological grade of the primary tumour, mitotic activity, Ki-67, and menstrual status. Of these, the ER-status was certainly of value as was its immunocytochemical equivalent performed on primary tumour tissue; low levels of ER correlated with early recurrence and a poor survival. This work has proved valuable in selection patients for adjuvant Tamoxifen therapy and has improved the clinical management of patients.

\section{PROSTATIC CANCER, STATISTICS AND ENDO- CRINOLOGY}

Douglas was a Founder Member of the British Prostate Study Group and in a similar way to breast cancer; prognostic factors have been sought for the clinical management of prostatic cancer patients. The application of multivariate statistical techniques to clinical and hormonal data obtained from patients with prostatic cancer, particularly data collected in collaboration with the Group, and with others such as Hanne Jensen, Department of Pathology, University California School of Medicine, Davis, California, has clearly implicated higher plasma growth hormone and lower plasma testosterone concentrations in the development of the disease. Life Table analysis of clinical data and those tissue markers of proliferative potential, such as Ki-67 have demonstrated that these markers may form the basis for selective treatment for prostatic cancer patients and for the selection of patients into specific arms of randomised clinical trials which call for either non-aggressive or aggressive forms of therapy. Some of this work was presented at Chulalongkorn University as part of the British Prostate Group activities.

The early work of Douglas also focussed on the role of the epididymis and ductus deferens in prostatic function; particularly the reduction of androgen-sensitive activity of RNA polymerase enzymes brought about by unilateral castration or unilateral vasectomy: work which may be relevant to any effect that human vasectomy may have on the development of benign prostatic hyperplasia.

Using a method for the measurement of plasma oestradiol by competitive protein binding as an example, research between $1969-71$, was directed towards an understanding of the physio-chemical kinetics of hormone-protein binding assay systems and of the method used to separate free from bound hormone. The integration of theoretical and practical aspects of this assay allowed the prediction of error profiles associated with the estimation of analyte concentration for different concentrations of binding protein and labelled analyte system. This work led to the evaluation of various statistical methods used to estimate the concentration of hormone in a sample, such as blood or saliva, from calibration curve data. The consequences of this research were of importance in cancer studies requiring precise and statistically unbiased hormone estimations, and were also of value in assessing the performance of laboratory methods used by participants in external quality assessment schemes.

A British Prostate Study Group investigation of plasma hormone levels in patients presenting with carcinoma of the prostate, initiated at the Tenovus Institute in the mid 1970's, resulted in a decade of research and development of efficient internal quality control techniques. These techniques, based on optimal cumulative sum schemes, were designed to monitor the mean level of analyte in a quality control pool, together with the imprecision and intra-assay drift. This allowed acceptable standards of quality to be maintained in the Institute's assay laboratories. This research also provoked a critical evaluation of national external quality assessment schemes that were currently practiced and a pilot external quality assessment scheme for plasma progesterone, conducted within the Institute, was introduced so as to allow more realistic assessments of bias and imprecision of the assay methods used by participants in the scheme, to be obtained. Against this background of improved statistical assessment of laboratory performance, plasma hormone measurements and clinical information from two cancer studies, breast and prostate, were analysed using multivariate statistical methods. Prognostic indices were also derived for predicting the survival of patients with advanced carcinoma of the prostate, which have potentially important implications in their clinical management.

A computer program was devised to monitor internal quality control schemes using the statistical concepts that had been developed. This initiated an important and continuing development of software for widespread use in routine clinical endocrinology and pathology laboratories. Another aspect of computing concerned simulation, which was used to determine the limitations of mass action models used to quantify oestradiol-receptor levels in human breast tumour cytosol. This work was important since levels of receptor can be used in the clinical management of patients with advanced breast cancer.

In the closing stages of his work at Tenovus, Dr Wilson worked on phyto-oestrogens seeking to use epidemiological and biochemical knowledge to promote healthy foods and was a guest speaker e.g. Phyto-oestrogens and breast cancer at the Royal Society of Edinburgh, 1992. Similarly he was an invited guest speaker at the Ettore Majorana Centre for Scientific Culture, Erice, Sicily (1992) Teaching Programme including Phyto-oestrogens and Cancer Risk.

Due to severe financial constraints, staff needed to seek alternative employment elsewhere and Dr Wilson was no exception. However, he was still, in a small way able to pursue his interests in Cancer and Chronomics with the help of Professor Griffiths and the unfailing support of Professor Halberg.

\section{RESEARCH 1992-2005. CANCER, CHRONOMICS AND AGRICULTURE}

Dr Wilson joined ADAS (Biometrics Unit, Rivershill House, St George's Road, Cheltenham, once part of Ministry of Agriculture Fisheries and Food (MAFF now DEFRA) and an Agency before being privatised in 1997) as a senior Scientist and Deputy Head of Unit: who later became Chief 
Statistician for ADAS Gleadthorpe Research Centre, Meden Vale, Mansfield, Nottinghamshire, NG20 9PF. His skills in physical, biological and numerical sciences were appropriate for the design and analyses of multifarious projects for Government, Institutions and Commercial bodies. While these probably number 1000 or more at a conservative estimate, little opportunity arose for publication of papers as work was largely confidential. His research activities comprised, inter alia, the following.

\section{STATISTICS}

Advice and hands on support was given on a wide range of applied statistics issues in agricultural-related projects in R\&D and consultancy comprising ADAS business. This broadly involves the choice/approval of experiment design, especially sampling schemes, followed by data management, analysis and presentation of material for reports for various areas of activity as follows:

\section{ARABLE CROPS AND HORTICULTURE}

Considerable experience in the use/advantages of a wide variety of designs has been gained/applied and includes fully randomised, simple randomised blocks, fully factorial, split plots, split-split plots, incomplete blocks, strip plots, Latin square and other designs or the development of non-classical designs when the occasion demands. The response variables have included presence/absence indicators of soil organisms, population size of same, disease categories, areas under disease/growth profiles as single entities or as repeated measures or more complicated systems such as responses to crop rotation. Using a variety of packages including Genstat, Minitab, and Statistica, analysis of data has included a wide variety of statistical techniques which include parametric and non-parametric (Friedman's test) analyses of variance with attendant Duncan and Dunnett's and other pairwise multiple range tests where appropriate. Extensive use has been made of a wide variety of data transformations for data/model compatibility. Experience has been developed in providing useful interpretations of the data when difficulties are encountered in practice e.g. those that may arise from missing data or from limits of detection of measurements. Linear and non-linear response data to fertiliser or other quantitative levels of treatment have been modelled using a wide range of regression functions.

More recently attention has been focussed on possible application areas for neural networks. Statistical advice is provided to consultants in horticulture on experiment design for the production of fruit, vegetables, nursery stock, flowers, plant propagation, weed control, evaluation of biological control agents, irrigation, plant nutrition, crop management, harvesting methods and the effects of pollution, and survey analysis.

\section{ENVIRONMENTAL POLLUTION AND RELATED PROJECTS}

These include time series analysis/repeated measures analysis from aerial $\mathrm{CO}_{2}$ and $\mathrm{NH}_{3}$ emission from crop residue incorporation into soils and $\mathrm{CH}_{4}, \mathrm{NH}_{3} \mathrm{~N}$ and $\mathrm{N}_{2} \mathrm{O}$ emis- sions from organic wastes including evaluation of analytical performance characteristics. Other studies include heavy metal pollution of land from manures and sewerage sludge; water pollution with insecticides; nitrate pollution of water from fertilisers; and phosphorous loadings in water, and assessment of paper sludge on $\mathrm{pH}$ of soil. The uptake of stable isotopes of calcium, lead, and strontium by beans, cabbages, and apples, simulating nuclear fall out e.g. Chernobyl have been conducted by Douglas at ADAS Rosemund, Hereford.

\section{EPIDEMIOLOGY/PLANT DISEASE}

Several studies involving an assessment of simulation models or the use of general linear modelling (GLM) programs or more special designs to study the epidemiology of plant diseases such as those caused by aphid-borne viruses, sclerotinia, botrytis and potato blight have been undertaken.

\section{MICROBIOLOGICAL POLLUTION}

Experience has been gained in the analysis of microbiological data for milk e.g. MAFF survey of farms in England and Wales. These data included colony counts, coliforms, E Coli, S Aureus, Listeria. Work for the Food Standards Agency has included the study of a wide number of organisms in meat e.g. abattoirs. Several ad hoc studies have also been undertaken and include manures from a variety of species and sources and their impact as a health risk in food, including shell fish. Although not specific to microbiology, experience is claimed in collaborative trials e.g. Youden and Steiner methodology that has been used in recent ADAS collaborative trials. As part of this methodology attention to detail has been necessary in trial design to elicit the intra and inter laboratory components of uncertainty for samples submitted for assay and analysis. More recent attention has been focussed at the development stage on methods-comparison studies for EC 0157 and reliable evaluation of monitoring same and other pathogens following organic waste treatments and subsequent application to land.

\section{ECOTOXICOLOGY}

Knowledge of statistical methods used in ecotoxicology has been gained (working with GLP criteria) and used in various pesticide programmes of work conducted within ADAS including those for pesticide services directorate (PSD). This work/knowledge and previous experience has focussed on experiment design, mortality/survival statistics, prognostic factors, lethal and quantal responses to stressors, species diversity indices (e.g. Shannon-Weaver) and a wide range of ordination methods used in ecology. Of particular importance was the chronobiological development of key aquatic or benthic organisms in the ecological communities of organisms existing in mesocosms and streams some of which swarmed during the day making experimentation difficult unless standardized.

\section{LIVESTOCK}

This has involved time series analyses e.g. activity of poultry during growth and development under different light and feeding regimens; and animal health issues such as envi- 
ronmental dust pollution in pig-houses. Experience in cancer research has mapped conveniently into skills for undertaking livestock studies such as vaccination trials and feeding experiments within the ADAS programme for livestock. Many experiments were conducted with colleagues in pig, sheep, cattle, and poultry sector.

\section{GENERAL STATISTICS}

A wide range of more general statistical skills has been applied to ADAS programmes of work that would be expected from a professional statistician, including survey work (and later in 2007 he conducted a survey at the University of Limerick for the Irish Research Council on women in academia). The latter includes a survey of skylarks and yellowhammers and related bird survey studies as they relate to ecology and data were analysed, inter alia, using GLM to evaluate the influence of crop, hedge and other factors on bird populations. He was an examiner in Operational Research, lectured at home and abroad, and spent a considerable time training others. The above represent a flavour rather than an exhaustive list of research activities.

\section{CONTINUED LIAISON WITH THE HALBERG CEN- TER FOR CHRONOBIOLOGY}

From 1991 to present, being part of BIOCOS (Biological Cosmology Group) he endeavoured to maintain his interest in chronomics (chronobiology) and conduct collaborative research whencesoever possible. He attended scientific meetings at Puschino (near Moscow 1993), Kosice (1997), Slovakia, University of Minneapolis, USA (July $5^{\text {th }} 1999$ ) and was an invited speaker to International Conference on 'Ambulatory Heart Rate Monitoring' in 'Time structureschronomes-in child development". Theodor-HellbruggeStiftung, Munich, Germany. November $\left.29^{\text {th }}-30^{\text {th }} 2002\right)$. He gave a Public address (February $5^{\text {th }} 2003$ ) to the Cardiff Scientific Society, Cardiff University, on Health Watch: Blood pressure Monitoring; and the BIOCOS'. By Halberg, F., Cornelissen, G. and Wilson D.W. As a member of the ADAS team and undertaking part of a Romanian Crop Survey 2003/2004 carried out with the Romanian National Institute for Statistics in Bucharest and the Romanian Ministry for Agriculture which led to two papers on chronomics.

There is also mention of his work in an extract from "Aslanyan N.L and Madoyan S Kh. (2002). The achievements of chronobiology and chronomedicine" by Professor Aslanyan, Department of Clinical Biochemistry, Armenian Medical Institute, Yerevan State University, Yerevan, Armenia.

\section{PHILOSOPHY OF SCIENTIFIC ENDEAVOUR AND TEAMWORK}

During his 50 years or so in research he has striven to involve others in his ethos of teamwork and in publications has endeavoured to include as co-author, even as first author, all those who have made a contribution towards a scientific publication. Similarly he has been a recipient of this ethos from Professors, Griffiths, Halberg, Singh and Hungin (Dean of School Medicine Pharmacy and Health, Durham University). It is not possible to trace all those who have been/are contributors to research; some are either deceased, or have moved to addresses unknown, and others would be extremely difficult to contact. Douglas was enthused by many chronobiologists, among them Professor Larry Scheving (chronoefficacy and chronotolerance: Little Rock, Arkansas). Professor Salvador Sanchez de la Pena (Diabetes, Metabolic Syndrome: Mexico), Pietro Cugini (Hyperbaric index: Rome), those in Minneapolis and scores of others who have been his delight, including Professor Hugh Simpson (Breast skin temperature rhythms: Glasgow). Douglas over the years highly valued one-to-one discussions such as those almost chosen at random with:- Professor John Adams, School of Biochemistry, University of New South Wales, Sydney (Steroid 16 $\alpha$ hydroxylase in breast-carcinoma tissue); Professor Otto Schmitt - Schmitt trigger fame- University Minnesota; Professor Charles Donaghey, Dept. Industrial Engineering, University of Houston, Texas. (CELLSIM. Simulation of Cell Cycles); Professor Bryan Hudson First professor of Medicine at Monash University, Prince Henry's Hospital Medical Research Centre, Melbourne(Measurement of hormones-testosterone by double isotope techniques); Professor Joseph DiStephano, III, Biocybernetics Laboratory, UCLA, Los Angeles (System dynamics -steroids); Professor R.L. Schaffer, National Measurement Laboratory, National Bureau of Standards, Washington D.C. (Accuracy of mass measurement); Dr David Rodbard, National Institutes of Health, NICHD, Bethesda, Maryland (Immunometric assays); Dr David Byar, Biometry Branch National Cancer Institute, Bethesda, Maryland (Models for analysing cohort studies - prognostic factors); Pietro Gullino, Laboratory of Pathophysiology, NIH (Natural history of breast cancer angiogenesis); Professor Luigi Castagnetta, University of Palermo, Sicily(Prostate disease); Professor Edmund Gehan, Department of Biostatistics, Bioinformatics, Biomathematics, Lombardi Comprehensive Cancer Center, George Washington University, Washington, DC. (Statistics in general); Professor Jean De Prins, Université Libre de Bruxelles, (Physics and rhythm analysis). However, all are highly valued and he is indebted to all those, probably thousands including his Tsim Tsoum colleagues, who have supported him over the years, including his school masters and those at the present time in the School of Medicine, Pharmacy and Health, Queen's Campus, Durham University.

(C) Douglas Wilson; Licensee Bentham Open.

This is an open access article licensed under the terms of the Creative Commons Attribution Non-Commercial License (http://creativecommons.org/licenses/by-nc/3.0/) which permits unrestricted, non-commercial use, distribution and reproduction in any medium, provided the work is properly cited. 